\title{
Kỷ lục 62 lân bại trận năm 2020
}

\author{
Ho Manh Toan \\ Centre for Interdisciplinary Social Research \\ Phenikaa University \\ Hanoi, 28-12-2020
}

ISR | Phenikaa Uni. (Hồ Mạnh Toàn; 24/12/2020, *Original preprint: https://osf.io/jaw4a/download) - Trong năm 2020, tôi đã bị thất trận tổng cộng 62 lần, với đủ thứ lý do khác nhau. Bại trận ở đây là nói tới các bản thảo nộp vào các tạp chí bị loại, không được chấp thuận công bố. Việc này với một đơn vị nghiên cứu như ISR là việc khổ sở đủ bề.

Một năm tới 62 lần bại trận cũng là kỷ lục của tôi tính đến lúc này. Chi tiết mọi người có thể xem ở Bảng 1 :

Bảng 1. 62 lần thất bại trong năm 2020

\begin{tabular}{|c|c|c|c|}
\hline No. & Date & Journal - Publisher & Manuscript ID \\
\hline 1 & $\begin{array}{l}\text { December 18, } \\
2020\end{array}$ & Strategic Entrepreneurship Journal- Wiley & SEJ-20-3749 \\
\hline 2 & $\begin{array}{l}\text { December 17, } \\
2020\end{array}$ & $\begin{array}{l}\text { Journal of Environment and Development- } \\
\text { SAGE }\end{array}$ & JED-20-0262 \\
\hline 3 & $\begin{array}{l}\text { December 12, } \\
2020\end{array}$ & Social Science Computer Review - SAGE & SSCR-20-0116 \\
\hline 4 & $\begin{array}{l}\text { November 25, } \\
2020\end{array}$ & Journal of Research in Reading - Wiley & $\begin{array}{l}\text { JRIR-2020-09- } \\
0143\end{array}$ \\
\hline 5 & $\begin{array}{l}\text { November 09, } \\
2020\end{array}$ & $\begin{array}{l}\text { Post-Communist Economies - Taylor \& } \\
\text { Francis }\end{array}$ & 209739612 \\
\hline 6 & $\begin{array}{l}\text { November 06, } \\
2020\end{array}$ & $\begin{array}{l}\text { Health Policy and Planning - Oxford } \\
\text { University Press }\end{array}$ & $\begin{array}{l}\text { HEAPOL-2020- } \\
\text { Oct-0816 }\end{array}$ \\
\hline 7 & $\begin{array}{l}\text { November 05, } \\
2020\end{array}$ & Significance - Wiley & $N / A$ \\
\hline 8 & November 04, & Heliyon-Cell Press & HELIYON-D-20- \\
\hline
\end{tabular}




\begin{tabular}{|c|c|c|c|}
\hline & 2020 & & 08136 \\
\hline 9 & October 31, 2020 & Journal of Asia Business Studies - Emerald & $\begin{array}{l}\text { JABS-10-2020- } \\
0419\end{array}$ \\
\hline 10 & October 28,2020 & $\begin{array}{l}\text { Journal of International Students - School } \\
\text { of Education, University of Louisiana at } \\
\text { Monroe }\end{array}$ & N/A \\
\hline 11 & October 20, 2020 & Management in Education - SAGE & MIE-20-115 \\
\hline 12 & October 19, 2020 & $\begin{array}{l}\text { British Journal of Educational Technology- } \\
\text { Wiley }\end{array}$ & $\begin{array}{l}\text { BJET-0706-Oct- } \\
\text { 2020-OMS }\end{array}$ \\
\hline 13 & October 13,2020 & Research in Economics - Elsevier & RIE-D-20-00020 \\
\hline 14 & October 11,2020 & $\begin{array}{l}\text { Journal of Environmental Psychology- } \\
\text { Elsevier }\end{array}$ & JEVP-D-20-00075 \\
\hline 15 & October 10, 2020 & Social Science \& Medicine - Elsevier & SSM-D-20-04617 \\
\hline 16 & October 10, 2020 & Big Data and Cognitive Computing - MDPI & $\begin{array}{l}\text { BDCC-796435 } \\
\text { (Withdrawn) }\end{array}$ \\
\hline 17 & October 8, 2020 & Royal Society Open Science - Royal Society & $\begin{array}{l}\text { RSOS-201732 } \\
\text { (Withdrawn) }\end{array}$ \\
\hline 18 & $\begin{array}{l}\text { September 22, } \\
2020\end{array}$ & $\begin{array}{l}\text { Games Studies - The Swedish Research } \\
\text { Council (Vetenskapsrådet); The Joint } \\
\text { Committee for Nordic Research Councils for } \\
\text { the Humanities and the Social Sciences; } \\
\text { Blekinge Institute of Technology; IT } \\
\text { University of Copenhagen; Lund University }\end{array}$ & N/A (Withdrawn) \\
\hline 19 & $\begin{array}{l}\text { September 20, } \\
2020\end{array}$ & One Earth-Cell Press & $\begin{array}{l}\text { ONE-EARTH-D- } \\
\text { 20-00290 }\end{array}$ \\
\hline 20 & $\begin{array}{l}\text { September 17, } \\
2020\end{array}$ & Global Environmental Change - Elsevier & GEC-D-20-00670 \\
\hline 21 & $\begin{array}{l}\text { September 16, } \\
2020\end{array}$ & $\begin{array}{l}\text { Journal of Risk and Financial Management- } \\
\text { MDPI }\end{array}$ & jrfm-927795 \\
\hline 22 & $\begin{array}{l}\text { September 16, } \\
2020\end{array}$ & Methods X-Elsevier & MEX-D-20-00498 \\
\hline 23 & $\begin{array}{l}\text { September 15, } \\
2020\end{array}$ & Reading Research Quarterly - Wiley & $\begin{array}{l}\text { RRQ-2020-09- } \\
0213\end{array}$ \\
\hline
\end{tabular}




\begin{tabular}{|c|c|c|c|}
\hline 24 & $\begin{array}{l}\text { September 15, } \\
2020\end{array}$ & Environment \& Behavior-SAGE & E\&B-20-0560 \\
\hline 25 & $\begin{array}{l}\text { September 14, } \\
2020\end{array}$ & Heliyon-Cell Press & $\begin{array}{l}\text { HELIYON-D-20- } \\
06160\end{array}$ \\
\hline 26 & $\begin{array}{l}\text { September 10, } \\
2020\end{array}$ & Games and Culture-SAGE & GAMES-20-0207 \\
\hline 27 & $\begin{array}{l}\text { September 2, } \\
2020\end{array}$ & Scientometrics - Springer & SCIM-D-20-01147 \\
\hline 28 & August 29,2020 & Nature Sustainability - Nature & $\begin{array}{l}\text { NATSUSTAIN- } \\
20087253\end{array}$ \\
\hline 29 & August 26,2020 & Journal of Informetrics - Elsevier & JOI_2020_498 \\
\hline 30 & August 26, 2020 & $\begin{array}{l}\text { Information Processing and Management- } \\
\text { Elsevier }\end{array}$ & IPM-D-20-00849 \\
\hline 31 & August 25,2020 & Higher Education Policy - Palgrave & HIEP-D-20-00214 \\
\hline 32 & August 23,2020 & IEEE Access - IEEE & $\begin{array}{l}\text { Access-2020- } \\
41172\end{array}$ \\
\hline 33 & August 23,2020 & Minerva-Springer & \begin{tabular}{|l} 
MINV-D-20- \\
00128
\end{tabular} \\
\hline 34 & August 23, 2020 & $\begin{array}{l}\text { Library and Information Science Research- } \\
\text { Elsevier }\end{array}$ & LIBINF_2020_292 \\
\hline 35 & August 21,2020 & IEEE Access - IEEE & $\begin{array}{l}\text { Access-2020- } \\
41276\end{array}$ \\
\hline 36 & August 17,2020 & $\begin{array}{l}\text { Journal of Risk and Financial Management- } \\
\text { MDPI }\end{array}$ & JRFM-861193 \\
\hline 37 & August 12,2020 & Business Research Quarterly - SAGE & BRQ-20-0330 \\
\hline 38 & August 12,2020 & Information Development-SAGE & ID-20-0241 \\
\hline 39 & August 09, 2020 & Compare - Taylor \& Francis & CCOM-2020-0255 \\
\hline 40 & August 07,2020 & Palgrave Communications - Nature & \begin{tabular}{|l} 
PALCOMMS- \\
02767R1
\end{tabular} \\
\hline 41 & August 06, 2020 & Nature Human Behaviour- Nature & $\begin{array}{l}\text { NATHUMBEHAV- } \\
200812069\end{array}$ \\
\hline 42 & August 04,2020 & $\begin{array}{l}\text { Higher Education Research \& Development } \\
\text { - Taylor \& Francis }\end{array}$ & CHER-2020-0565 \\
\hline 43 & July 30,2020 & Asia Pacific Education Review -Springer & APER-D-20-00483 \\
\hline
\end{tabular}




\begin{tabular}{|c|c|c|c|}
\hline 44 & July 15,2020 & $\begin{array}{l}\text { Science Editing - Korean Council of Science } \\
\text { Editors }\end{array}$ & SE-20-044 \\
\hline 45 & July 15,2020 & Science Advances - AAAS & abd6622 \\
\hline 46 & July 10,2020 & $\begin{array}{l}\text { Studies in Higher Education - Taylor \& } \\
\text { Francis }\end{array}$ & CSHE-2020-0887 \\
\hline 47 & July 9,2020 & Higher Education - Springer & $\begin{array}{l}\text { HIGH-D-20- } \\
00831\end{array}$ \\
\hline 48 & July 9,2020 & $\begin{array}{l}\text { Journal of International Students - School } \\
\text { of Education, University of Louisiana at } \\
\text { Monroe }\end{array}$ & N/A \\
\hline 49 & July 5, 2020 & $\begin{array}{l}\text { Science and Public Policy- Oxford } \\
\text { University Press }\end{array}$ & SPP-2020-110 \\
\hline 50 & July 04,2020 & Science-AAAS & abd4132 \\
\hline 51 & June 26,2020 & Quantitative Science Studies - MIT Press & QSS-2020-0054 \\
\hline 52 & June 22,2020 & $\begin{array}{l}\text { Research Evaluation - Oxford University } \\
\text { Press }\end{array}$ & $\begin{array}{l}\text { RESEVAL-2020- } \\
0078\end{array}$ \\
\hline 53 & June 17,2020 & PNAS & MS\# 2020-11338 \\
\hline 54 & May 27,2020 & $\begin{array}{l}\text { Asia Pacific Journal of Education - Taylor \& } \\
\text { Francis }\end{array}$ & CAPE-2020-0146 \\
\hline 55 & May 15,2020 & Journal of Informetrics - Elsevier & JOI_2020_278 \\
\hline 56 & May 14,2020 & Learned Publishing - Wiley & $\begin{array}{l}\text { LEAP-20-May- } \\
0058\end{array}$ \\
\hline 57 & April 17, 2020 & $\begin{array}{l}\text { Mathematical and Computational } \\
\text { Applications - MDPI }\end{array}$ & mca-785831 \\
\hline 58 & March 31, 2020 & Palgrave Communications - Nature & $\begin{array}{l}\text { PALCOMMS- } \\
02811\end{array}$ \\
\hline 59 & March 30, 2020 & Big Data and Cognitive Computing - MDPI & BDCC-764207 \\
\hline 60 & March 19, 2020 & $\begin{array}{l}\text { Science Editing - Korean Council of Science } \\
\text { Editors }\end{array}$ & SE-20-016 \\
\hline 61 & March 2, 2020 & Higher Education Policy - Palgrave & HIEP-D-20-00039 \\
\hline 62 & January 13,2020 & Scientometrics - Springer & SCIM-D-19-01190 \\
\hline
\end{tabular}


Vượt qua được 62 lần thất bại đó, cuối cùng tôi có niềm vui đọng lại với 19 ấn phẩm đã được chấp nhận đăng trên các tạp chí [1-19], ngoài ra một bài viết đã ra mắt nhưng số xuất bản tính vào năm 2021 [20].

Con số 20 công bố quốc tế trong một năm không hề nhỏ, dù là với ai đi nữa. Nhưng để đạt được nó, tôi phải đối diện với 25 lần thất bại chỉ tính riêng trong 3 tháng hè nóng bỏng. Trung bình, mỗi lần nộp tiêu tốn khoảng 10-14 ngày chờ đợi chỉ để nhận được 'trái đắng.' Có những tạp chí còn bắt tác giả đợi nguyên cả tháng ròng từ khi nộp cho đến lúc có biên tập viên nhận xử lý bản thảo (ngay sau đó là reject liền tay). Cay đắng hơn cả là những lần bị từ chối vì các lý do rất 'chuối' như' chưa làm đúng định dạng của tạp chí, hay không chấp nhận các bản thảo đã có (un-peer-reviewed) preprints.

Khép lại năm 2020 nhiều biến động, tôi cảm ơn những lần thất bại giữa những tháng hè khắc nghiệt của Hà Nội đã dạy cho mình sự khiêm nhường. Hướng tới 2021 với những mục tiêu mới, hy vọng tôi có thể làm bảng thống kê thất bại năm 2021 dài lên gấp đôi hoặc gấp ba.

Dưới đây là bức thư Nature từ chối đăng một công trình mà sau này giành giải Nobel Sinh Y năm 2019 [21]: 


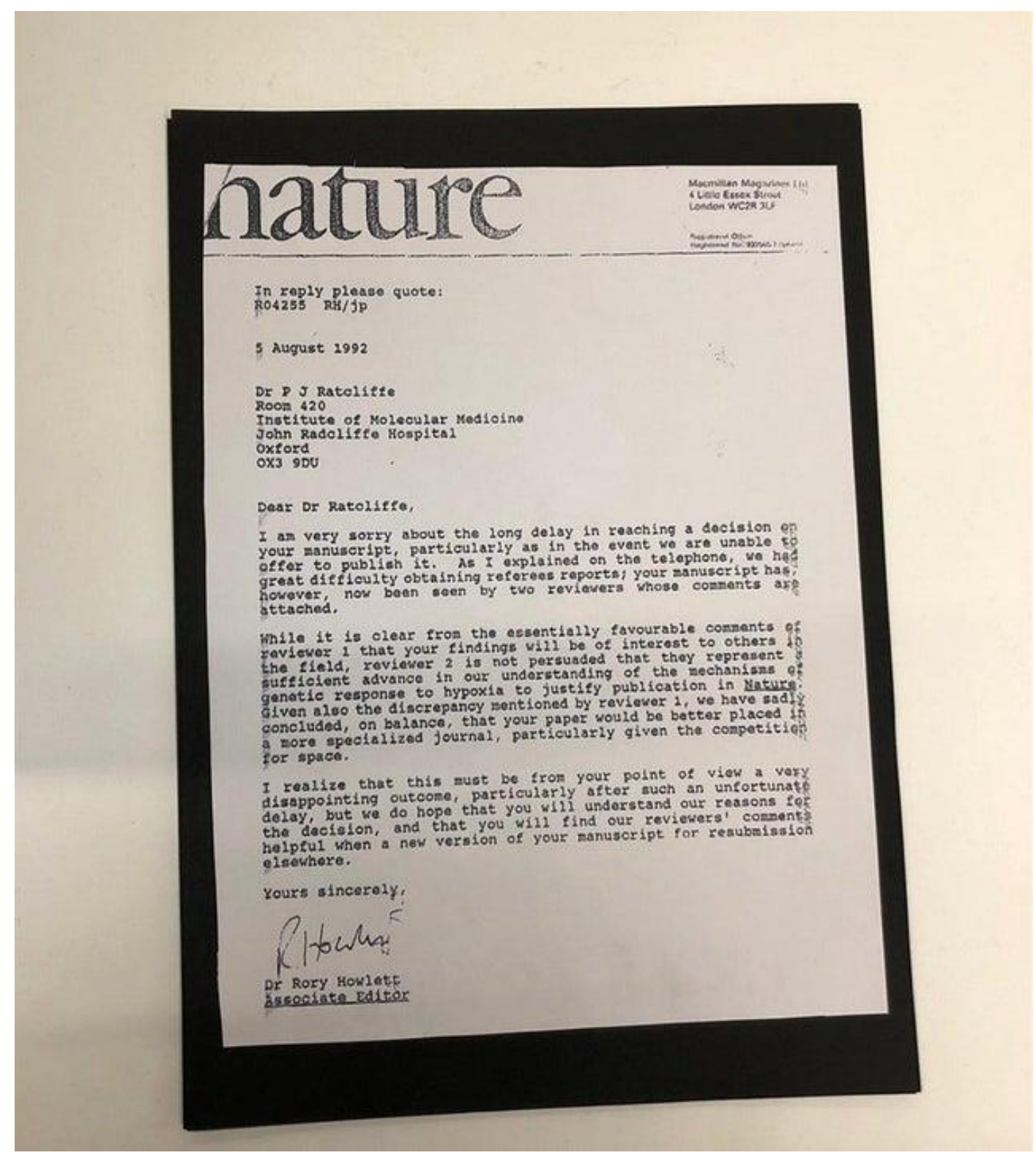

Thú vị ở chỗ, ở Trung tâm ISR không ai lo lắng mỗi lần báo tin bại trận. Người thầy phụ trách luôn sẵn sàng nghe tin thất trận, và rồi cho ra kiến giải về lý do thất bại rất đáng học.

Tôi cảm thấy kỳ quặc vì bại trận lại cũng thấy vui, và cũng lại thấy vui khi có ông thầy kỳ quặc thản nhiên nghe tin bại trận ít nhất là 62 lần.

\section{Tham khảo}

[1] Vuong, Q. H., \& Ho, M. T. (2020). Rethinking editorial management and productivity in the COVID-19 pandemic. European Science Editing, 46, e56541, doi: 10.3897/ese.2020.e56541. 
[2] Ho, M. T., La, V. P., Nguyen, M. H., Pham, T. H., Vuong, T. T., et al. (2020). An analytical view on STEM education and outcomes: Examples of the social gap and gender disparity in Vietnam. Children and Youth Services Review, 119, 105650, DOI: 10.1016/j.childyouth.2020.105650.

[3] Vuong, Q. H., La, V. P., Nguyen, T. H. K., Ho, M. T., Vuong, T. T., \& Ho, M. T.. (2020). Identifying the moral-practical gaps in corporate social responsibility missions of Vietnamese firms: An event-based analysis of sustainability feasibility. Corporate Social Responsibility and Environmental Management, DOI: 10.1002/csr.2029.

[4] Vuong, T. T., Ho, M. T., Nguyen, M. H., Nguyen, T. H. T., Nguyen, T. D., et al. (2020). Adopting open access in the social sciences and humanities: evidence from a developing nation. Heliyon, 6(7), e04522, DOI: 10.1016/j.heliyon.2020.e04522.

[5] Ho, M. T., Vuong, T. T., Pham, T. H., Luong, A. P., Nguyen, T. N., \& Vuong, Q. H. (2020). The internal capability of Vietnam social sciences and humanities: A perspective from the 2008-2019 dataset. Publications, 8(2), 32, DOI: $10.3390 /$ publications 8020032 .

[6] Vuong, Q. H., La, V. P., Nguyen, M. H., Ho, M. T., \& Ho, M. T. (2020). Bayesian analysis for social data: $A$ step-by-step protocol and interpretation. MethodsX, 7, 100924, doi: 10.1016/j.mex.2020.100924.

[7] Pham, T. H., Ho, M. T., Vuong, T. T., Nguyen, M. C., \& Vuong, Q. H. (2020). Entrepreneurial finance: Insights from English language training market in Vietnam. Journal of Risk Financial Management, 13(5), 96, DOI: $10.3390 / \mathrm{jrfm} 13050096$.

[8] Tran, T., Ho, M. T., Pham, T. H., Nguyen, M. H., Nguyen, K. L. P., et al. (2020). How digital natives learn and thrive in the digital age: Evidence from an emerging economy. Sustainability, 12(9), 3819, DOI: $10.3390 /$ su12093819.

[9] Vuong, Q. H., Ho, M. T., Nguyen, H. K. T., Vuong, T. T., Tran, T., et al. (2020). On how religions could accidentally incite lies and violence: Folktales as a cultural transmitter. Palgrave Communications, 6, 82, doi:10.1057/s41599-020-0442-3.

[10] Vuong, Q. H., La, V. P., Nguyen, M. H., Ho, M. T., Ho, M. T., \& Mantello, P. (2020). Improving Bayesian statistics understanding in the age of Big Data with the bayesvl R package. Software Impacts, 4, 100016, DOI: 10.1016/j.simpa.2020.100016. 
[11] Vuong, Q. H., La, V. P., Vuong, T. T., Nguyen, H. K. T., Ho, M. T., \& Ho, M. T. (2020). What have Vietnamese scholars learned from researching entrepreneurship? A Systematic review. Heliyon, 6(4), e03808, DOI: 10.1016/j.heliyon.2020.e03808.

[12] Vuong, Q. H., La, V. P., Vuong, T. T., Hoang, P. H., Ho, M. T., \& Ho, M. T. (2020). Multi-faceted insights of entrepreneurship facing a fast-growing economy: A literature review. Open Economies, 3(1), 25-41, DOI: 10.1515/openec-2020-0002.

[13] La, V. P., Pham, T. H., Ho, M. T., Nguyen, M. H., P Nguyen, K. L., et al. (2020). Policy response, social media and science journalism for the sustainability of the public health system amid the COVID-19 outbreak: The Vietnam lessons. Sustainability, 12(7), 2931, DOI: $10.3390 /$ su12072931.

[14] Nguyen, T. H. T., Tran, T., Dau, T. T., Nguyen, T. S. H., Nguyen, T. H., \& Ho, M. T. (2020). How scientific research changes the Vietnamese higher education landscape: Evidence from social sciences and humanities between 2008 and 2019. F1000Research, 9, 152, DOI: 10.12688/f1000research.21790.1.

[15] Vuon, Q. H., Le, A. V., La, V. P., Hoang, P. H., \& Ho, M. T. (2020). Making social sciences more scientific: Literature review by structured data. MethodsX, 100818. DOI: 10.1016/j.mex.2020.100818

[16] Vuong, Q. H., La, V. P., Ho, M. T., Vuong, T. T., \& Ho, M. T. (2020). Characteristics of retracted articles based on retraction data from online sources through February 2019. Science Editing, 71$), 34-44 m, D O I:$ $10.6087 / \mathrm{kcse} .187$

[17] Nguyen, M. H., Ho, M. T., La, V. P., Nguyen, Q. Y. T., Ho, M. T., et al. (2020). A scientometric study on depression among university students in East Asia: Research and system insufficiencies?. Sustainability, 12(4), 1498, DOI: $10.3390 /$ su12041498.

[18] Tran, T., Hoang, K. L., La, V. P., Ho, M. T., \& Vuong, Q. H. (2020). Scrambling for higher metrics in the Journal Impact Factor bubble period: a real-world problem in science management and its implications. Problems and Perspectives in Management, 18(1), 48-56, DOI: 10.21511/ppm.18(1).2020.05.

[19] Vuong, Q. H., La, V. P., Vuong, T. T., \& Ho, M. T. (21 Apr, 2020). Earth Hour in Vietnam: a perspective from the electricity industry. Behavioural and Social Sciences at Nature Research. URL: 
https://socialsciences.nature.com/users/301097-ho-manh-

toan/posts/66561-earth-hour-in-vietnam-a-perspective-from-the-

electricity-industry

[20] Nguyen, M. H., Pham, T. H., Ho, M. T., Nguyen, H. T. T., \& Vuong, Q. H. (2021). On the social and conceptual structure of the 50-year research landscape in entrepreneurial finance. SN Business \& Economics, 1, 2, DOI: 10.1007/s43546-020-00002-z.

[21] Italie, H. (2019). Not so fast: Many Nobel winners endured initial rejections. $A P \quad$ News. Retrieved from https://apnews.com/article/a85ac210de58448797735d7d5b04779c 